\title{
Evaluasi Pemanfaatan Waduk Wonorejo Sebagai Pengendali Banjir Kota Balikpapan
}

\author{
Evaluation of the Utilization Wonorejo Reservoir as Flood Control in \\ Balikpapan City
}

\author{
Ezra. H. Pongtuluran ${ }^{l)}$, Hadi Hermansyah ${ }^{2)}$ \\ Teknik Sipil, Politeknik Negeri Balikpapan \\ Jl. Soekarno Hatta Km.08 Balikpapan, Indonesia \\ 1)ezra.hartarto@poltekba.ac.id, ${ }^{21}$ hadi.hermansyah@poltekba.ac.id
}

\begin{abstract}
ABSTRAK
Saat ini telah telah dilakukan pembangunan beberapa waduk pada beberapa titik kawasan dengan tujuan sebagai pengendali banjir yang selama ini melanda Kota Balikpapan. Namun ternyata alternatif tersebut masih belum mampu mengurangi terjadinya genangan air di beberapa lokasi, termasuk pada kawasan Wonorejo, sehingga masih perlu dilakukan evaluasi terkait fungsionalnya sebagai bangunan pengendali atau hanya sekedar menjadi kolam tampungan air yang tidak memiliki sistem kontrol pelepasan air. Dalam menyelesaikan masalah tersebut, dilakukan analisis karakteristik wadukyang merupakan hubungan antara elevasi, luas dan kapasitas tampungan waduk dimana didapatkan menggunakan persamaan regresi polinomial orde 3. Kemudian, dilakukan proyeksi jumlah komulatif volume aliran masuk dalam waduk menggunakan persamaan program linear terhadap kapasitas tampungan waduk. Dalam mengetahui kinerja daya tampung saluran keluaran (outflow) maka dilakukan perbandingan terhadap debit masukan (inflow) pada waduk sebagai evaluasi mengetahui saluran outflow tidak akan terjadi luapan ke kawasan sekitar. Berdasarkan kurva karakteristik didapatkan kapasitas tampungan dalam waduk Wonorejo adalah sebesar 0,795 MCM atau 794.900,45 $\mathrm{m}^{3}$ dengan total keselurahan volume yang masuk dalam waduk sebesar $1.795 .034 \mathrm{~m}^{3}$ yang menunjukkan bahwa kinerja waduk saat ini telah telah kurang efektif. Sedangkan pada kapasitas saluran pembuang (outflow) waduk didapatkan $57,90 \mathrm{~m}^{3} / \mathrm{s}$, apabila dibandingkan dengan besaran debit yang masuk (inflow) sebesar $33,00 \mathrm{~m}^{3} / \mathrm{s}$ maka dapat dikatakan dimensi saluran outflow masih cukup memiliki kapasitas dalam menampung debit banjir dari dalam waduk.
\end{abstract}

Kata kunci: banjir, kinerja waduk, kapasitas saluran.

\section{ABSTRACT}

Several reservoirs have been built at several points in the area to control the floods that have been hitting Balikpapan City. However, it turns out that this alternative is still not able to reduce the occurrence of standing water in several locations, including in the Wonorejo area, so it still needs to be evaluated regarding its function as a control building or merely being a water storage pool that does not have a water release control system. In solving this problem, an analysis of the reservoir's characteristics is carried out, which is the relationship between elevation, area, and reservoir capacity, which is obtained using the $3^{\text {rd }}$ order polynomial regression equation. Then, the cumulative volume of inflow volume projection in the reservoir is carried out using a linear program equation to the reservoir capacity. In knowing the output channel capacity (outflow) performance, a comparison is made to the input discharge (inflow) in the reservoir as an evaluation to find out that the outflow channel will not overflow into the surrounding area. Based on the characteristic curve, it is found that the storage capacity in the Wonorejo reservoir is $0.795 \mathrm{MCM}$ or $794,900.45 \mathrm{~m}^{3}$ with the total volume entering the reservoir of $1,795,034 \mathrm{~m}^{3}$, which indicates that the current performance of the reservoir has been less effective. Whereas in the reservoir outflow capacity, it was found $57.90 \mathrm{~m}^{3} / \mathrm{s}$, when compared to the amount of input discharge (inflow) of $33.00 \mathrm{~m}^{3} / \mathrm{s}$, it can be said that the dimensions of the outflow channel still have sufficient capacity to accommodate flood discharge from within reservoir.

Keywors: flood, reservoir performance, channel capacity

\section{PENDAHULUAN}

Dalam 10 tahun terakhir, peningkatan frekuensi kejadian banjir di Kota Balikpapan semakin meningkat dari waktu ke waktu diikuti dengan peningkatan jumlah lokasi titik genangan air.
Manajemen atau pengelolaan limpasan air hujan yang baik sangat dibutuhkan untuk menekan terjadinya bencana maupun kerugian ekonomi yang lebih tinggi akibat banjir. Pengelolaan pemanfaatan ruang dan limpasan air hujan perlu dilakukan dengan keseriusan 
dan konsistensi terhadap target dan tujuan yang ingin dicapai (Heri Susanto).

Dalam hal ini, Pemerintah Kota Balikpapan telah melakukan beberapa pembangunan bendungan pengendali (Bendali) pada beberapa titik kawasan dengan tujuan genangan aliran dapat masuk pada bendali tersebut. Namun ternyata alternatif tersebut masih belum mampu mengurangi terjadinya genangan air di beberapa lokasi, termasuk pada kawasan Wonorejo, sehingga masih perlu dilakukan evaluasi terkait fungsionalnya sebagai bendungan pengendali atau hanya sekedar menjadi kolam tampungan air yang tidak memiliki sistem kontrol pelepasan air.

Dengan meninjau uraian di atas dan permasalaahan yang terjadi maka tujuan dari penelitian ini adalah:

1. Menelusuri kondisi kapasitas tampungan waduk,

2. Mengetahui kemampuan waduk dalam pengendalian banjir,

3. Mengevaluasi kinerja saluran waduk dalam pembuangan air berlebihan.

Hasil penelitian ini diharapkan dapat bermanfaat untuk menghasilkan informasi dan rekomendasi sebagai bahan pertimbangan bagi pengambil kebijakan dalam pengelolaan waduk berkelanjutan terkait dengan kinerja kapasitas tampungan, saluran inflow dan outflow pada waduk.

\section{KARAKTERISTIK WADUK}

Prinsip dalam pengoperasian waduk membutuhkan banyak informasi tentang karakterisitk fisik yang diperlukan. Salah satunya adalah hubungan antara elevasi dan volume tampungan serta luas permukaan genangan (Sudjarwadi, 2008). Hubungan ini ditentukan berdasarkan pengukuran topografi. Contoh bentuk Kurva karakteristik Waduk dapat dilihat pada Gambar 1.

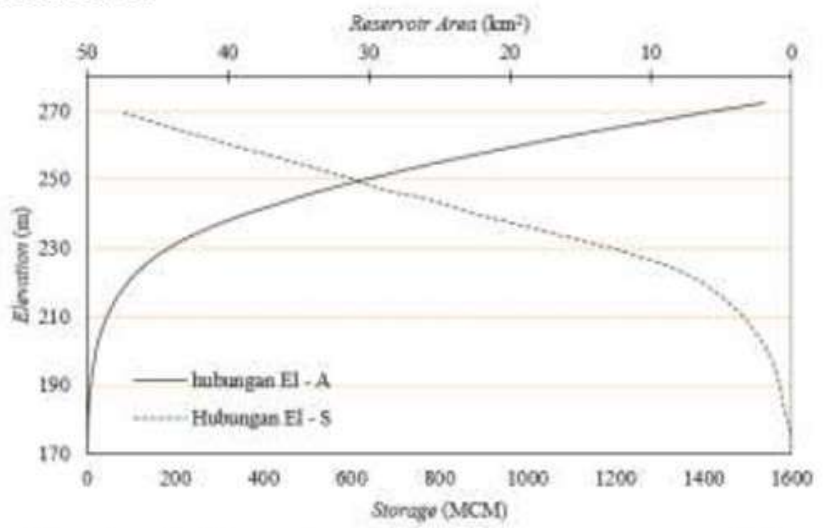

Gambar 1. Kurva karakteristik tampungan waduk

Fungsi hubungan antara elevasi dan volume waduk umumnya terdiri dari dua atau tiga bagian. Bagian awal sifat umumnya sangat berbeda dengan bagian akhir dengan bentuk cekungan embung tidak teratur
(Sri Harto, 2009). Simulasi tampungan waduk memerlukan persamaan yang menggambarkan pengaruh elevasi terhadap luas genangan. Dalam menentukan persamaan tersebut, diperlukan analisis regresi dengan bantuan pada program Microsoft Excel.

Hasil regresi dengan bantuan Microsoft Excel didapatkan persamaan hubungan antara elevasi dengan volume tampungan waduk dan elevasi dengan luas genangan waduk. Hubungan antara elevasi dan volume tampungan digunakan untuk mengetahui fluktuasi elevasi muka air waduk sedangkan hubungan antara elevasi dengan luas genangan waduk digunakan untuk mengetahui besarnya penguapan yang terjadi.

\section{DEBIT ALIRAN}

Debit aliran merupakan ukuran banyaknya volume air yang dapat lewat dalam suatu tempat atau yang dapat di tampung dalam suatu tempat tiap satuan waktu. Dalam menghitung debit aliran, dapat menggunakan metode rasional. Namun penggunaan metode rasional masih terdapat beberapa kekurangan antara lain: daya tampung daerah penangkapan hujan tidak diperhitungkan, hujan diperkirakan merata pada seluruh daerah tangkapan hujan, hidrograf dari aliran tidak bisa digambarkan.

Mengurangi kelemahan tersebut, maka metode ini kemudian dimodifikasi yang disebut sebagai "Modifikasi Rasional". Debit saluran yang akan diperiksa kapasitasnya, dihitung sebagai berikut:

$$
\begin{aligned}
& Q=\frac{1}{3,6} \cdot \mathrm{C} \cdot \mathrm{C}_{\mathrm{s}} \cdot \mathrm{I} \cdot \mathrm{A} \\
& C_{s}=\frac{2 t_{c}}{2 t_{c}+t_{d}}
\end{aligned}
$$

Keterangan:

$\mathrm{Q}=$ debit aliran air $\left(\mathrm{m}^{3} / \mathrm{jam}\right)$

$\mathrm{C}=$ koefisien pengaliran rata-rata

$\mathrm{C}_{\mathrm{s}}=$ Koefisien penyimpanan

$\mathrm{I}=$ intensitas curah hujan ( $\mathrm{mm} / \mathrm{jam})$

$\mathrm{A}=$ luas daerah layanan $\left(\mathrm{km}^{2}\right)$

$\mathrm{t}_{\mathrm{c}}=$ waktu konsentrasi, untuk daerah saluran drainase terdiri dari $t_{0}$ dan $t_{d}$ (menit)

$\mathrm{t}_{0}=$ Waktu yang diperlukan air untuk mengalir melalui permukaan tanah ke saluran terdekat (menit)

$\mathrm{t}_{\mathrm{d}}=$ Waktu yang diperlukan air untuk mengalir dalam saluran ke tempat waktu yang direncanakan (menit)

Berdasarkan kolerasi antara waktu aliran puncak dan waktu kosentrasi aliran dapat dibuat suatu hidrograf aliran masuk dengan menggunakan persamaan linear seperti yang ditunjukkan pada Gambar 2. 


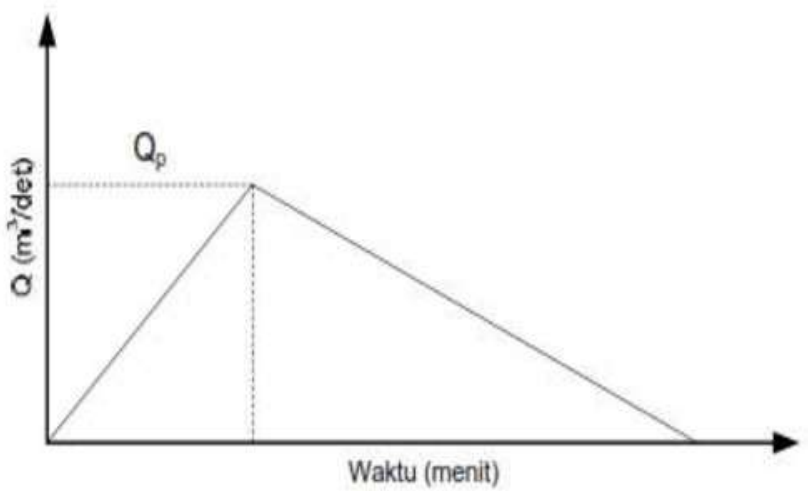

Gambar 2. Skematik unit hidrograf

\section{PENELUSURAN ALIRAN}

Penelusuran aliran adalah prosedur untuk menentukan waktu dan debit aliran (hidrograf aliran) di suatu titik pada aliran berdasarkan hidrograf yang diketahui di sebelah hulu. Apabila aliran tersebut adalah banjir, maka prosedur tersebut dikenal dengan penelusuran banjir.

Penelusuran aliran dinyatakan dalam bentuk persamaan kontinuitas, yaitu:

$$
\mathrm{I}-\mathrm{O}=\Delta \mathrm{S} / \Delta \mathrm{t}
$$

Keterangan:

I = aliran masuk (inflow) ke ruas sungai $\left(\mathrm{m}^{3} /\right.$ detik)

$\mathrm{O}=$ aliran keluar (outflow) dari sungai $\left(\mathrm{m}^{3} /\right.$ detik)

$\Delta \mathrm{S}=$ perubahan tampungan (storage) sungai $\left(\mathrm{m}^{3}\right)$

$\Delta \mathrm{t}=$ interval waktu penelusuran (detik, jam, hari)

\section{KINERJA OPERASI WADUK}

Waduk adalah fasilitas tampungan yang dibuat untuk menampung air selama debit tinggi dan mengeluarkannya pada saat dibutuhkan, sehingga fungsi waduk secara prinsip ialah menampung air pada saat-saat debit tinggi sehingga dapat digunakan pada saat-saat debit sangat rendah. Beberapa indikator untuk menilai besarnya performance operasi waduk dapat meliputi keandalan (reliability), kelentingan (resiliency) dan kerawanan (vulnerability).

\section{EVALUASI KINERJA SALURAN WADUK}

Kinerja sistem saluran waduk melayani penerimaan dan pembuangan kelebihan air dari suatu kawasan dengan cara mengalirkannya ke pembuangan akhir, seperti sungai, danau, atau laut baik melalui permukaan tanah maupun bawah permukaan tanah untuk menghindari terjadinya genangan air. Kelebihan air tersebut berasal tidak hanya dari buangan air hujan, tetapi juga dari air limbah domestik dan industri, namun yang paling dominan adalah air hujan (Suripin, 2004).

\section{METODOLOGI PENELITIAN}

Lokasi penelitian akan dilaksanakan di Kota Balikpapan dimana objek penelitian difokuskan pada kawasan Waduk Wonorejo seperti yang ditunjukkan pada Gambar 3 dengan luas DAS sebesar 3,5 km²

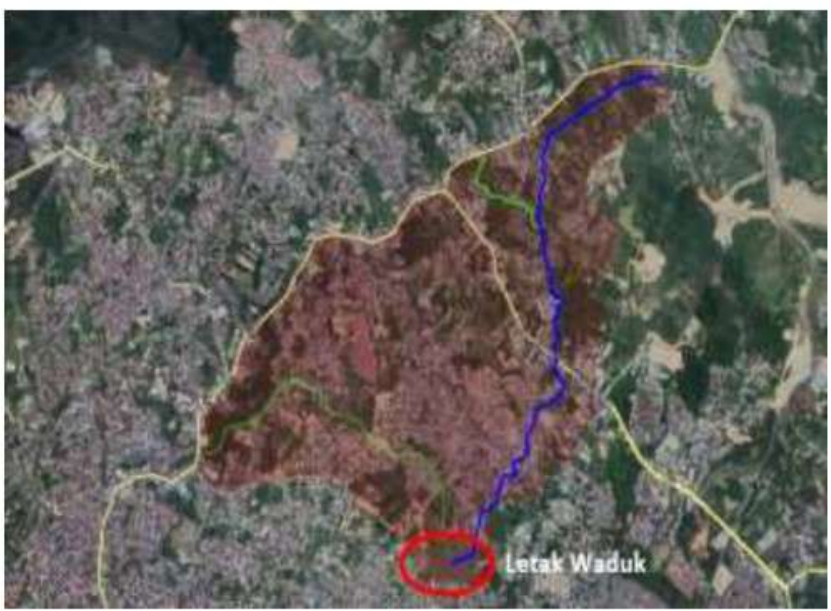

Gambar 3. Peta DAS waduk Wonorejo

Tahapan penelitian dilakukan melalui beberapa tahap yang dapat digambarkan dalam bagan alir penelitian pada Gambar 4.

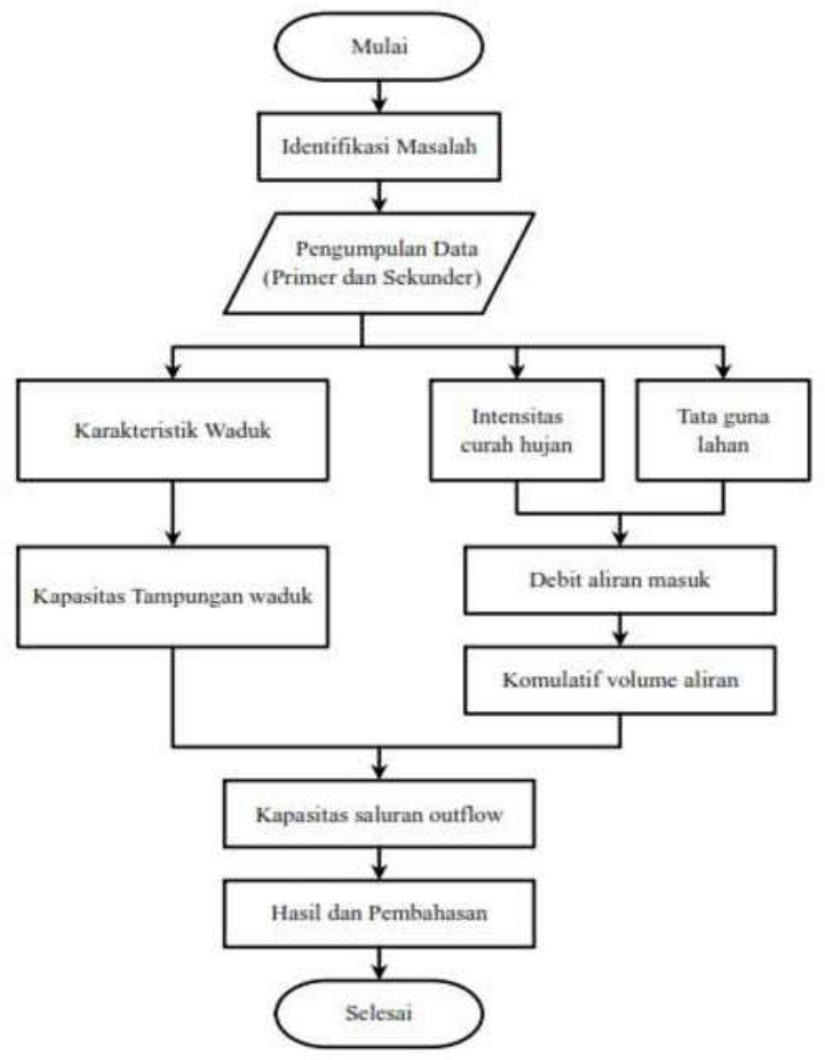

Gambar 4. Bagan alir penelitian

\section{KARAKTERISTIK TAMPUNGAN WADUK}

Nilai elevasi didasarkan dari ketinggian kontur waduk yaitu $13 \mathrm{~m}$ dari atas permukaan laut dan dalam 
perencanaan tampungan pengendalian banjir digunakan elevasi ketinggian muka air banjir sehingga total berdasarkan elevasi waduk sebesar $33,46 \mathrm{~m}$ seperti pada Tabel 1.

Tabel 1. Elevasi, kapasitas tampungan dan luas genangan Waduk Wonorejo

\begin{tabular}{|c|c|c|c|c|c|c|}
\hline \multirow{2}{*}{ No } & \multirow{2}{*}{$\begin{array}{c}\text { Elevasi } \\
\text { Kontur } \\
\text { (m) }\end{array}$} & \multirow{2}{*}{$\begin{array}{l}\text { Luas } \\
\left(\mathrm{m}^{2}\right)\end{array}$} & \multirow{2}{*}{$\begin{array}{c}\text { Interval } \\
\text { (m) }\end{array}$} & \multirow{2}{*}{$\begin{array}{c}\text { Volume } \\
\left(\mathrm{m}^{3}\right)\end{array}$} & \multicolumn{2}{|c|}{ Total Volume } \\
\hline & & & & & $\left(\mathrm{m}^{3}\right)$ & (MCM) \\
\hline 1 & 13 & $7.000,00$ & & & 0 & 0,000 \\
\hline 2 & 14 & $8.026,50$ & 1,00 & $7.513,25$ & $7.513,25$ & 0,008 \\
\hline 3 & 15 & $9.206,86$ & 1,00 & $8.616,68$ & $16.129,93$ & 0,016 \\
\hline 4 & 16 & $10.560,80$ & 1,00 & $9.883,83$ & $26.013,76$ & 0,026 \\
\hline 5 & 17 & $12.113,84$ & 1,00 & $11.337,32$ & $37.351,08$ & 0,037 \\
\hline 6 & 18 & $13.895,27$ & 1,00 & $13.004,56$ & $50.355,64$ & 0,050 \\
\hline 7 & 19 & $15.938,68$ & 1,00 & $14.916,98$ & $65.272,61$ & 0,065 \\
\hline 8 & 20 & $18.282,58$ & 1,00 & $17.110,63$ & $82.383,24$ & 0,082 \\
\hline 9 & 21 & $20.971,17$ & 1,00 & $19.626,88$ & $102.010,12$ & 0,102 \\
\hline 10 & 22 & $24.055,14$ & 1,00 & $22.513,16$ & $124.523,28$ & 0,125 \\
\hline 11 & 23 & $27.592,63$ & 1,00 & $25.823,89$ & $150.347,16$ & 0,150 \\
\hline 12 & 24 & $31.650,34$ & 1,00 & $29.621,48$ & $179.968,65$ & 0,180 \\
\hline 13 & 25 & $36.304,76$ & 1,00 & $33.977,55$ & $213.946,19$ & 0,214 \\
\hline 14 & 26 & $41.643,64$ & 1,00 & $38.974,20$ & $252.920,39$ & 0,253 \\
\hline 15 & 27 & $47.767,66$ & 1,00 & $44.705,65$ & $297.626,05$ & 0,298 \\
\hline 16 & 28 & $54.792,25$ & 1,00 & $51.279,95$ & $348.906,00$ & 0,349 \\
\hline 17 & 29 & $62.849,86$ & 1,00 & $58.821,06$ & $407.727,06$ & 0,408 \\
\hline 18 & 30 & $72.092,41$ & 1,00 & $67.471,14$ & $475.198,19$ & 0,475 \\
\hline 19 & 31 & $82.694,14$ & 1,00 & $77,393,28$ & $552.591,47$ & 0,553 \\
\hline 20 & 32 & $94.854,94$ & 1,00 & $88.774,54$ & $641.366,01$ & 0,641 \\
\hline 21 & 33 & $108.804,07$ & 1,00 & $101.829,51$ & 743.195 .51 & 0,743 \\
\hline 22 & 33,46 & $116.000,00$ & 0,46 & $51.704,94$ & $794.900,45$ & 0,795 \\
\hline
\end{tabular}

Kemudian dibentuk kurva karakteristik tampungan waduk diperlukan untuk mengetahui hubungan antara elevasi (elevation), luas genangan (area) dan volume (storage) waduk. Kurva karakteristik tampungan waduk Wonorejo dapat dilihat pada Gambar 5.

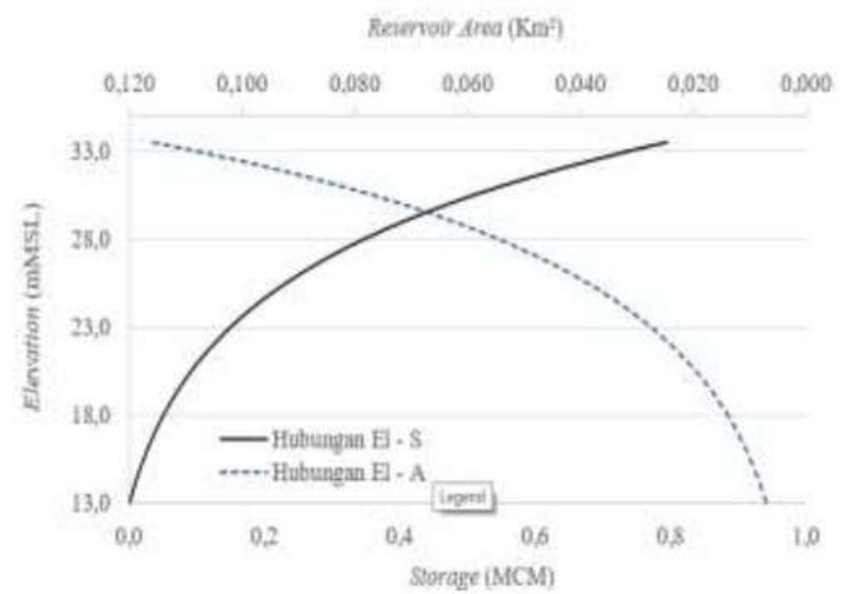

Gambar 5. Kurva karakteristik Waduk Wonorejo

Pada karakteristik waduk didapatkan total volume tampungan waduk sebesar $0,795 \mathrm{MCM}$ atau $794.900,45 \mathrm{~m}^{3}$.

Kurva elevasi-volume genangan dapat dibuat persamaan yang menghubungkan keduanya, sehingga hasil pengukuran lapangan dapat dikontrol menggunakan suatu persamaan yang terbentuk dengan menggunakan seperti pada Gambar 6 . .

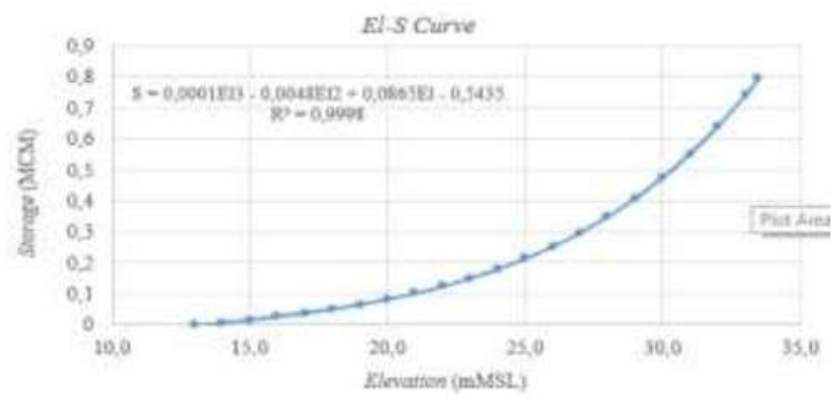

Gambar 6. Kurva elevasi-volume Waduk Wonorejo

Dengan mengetahui elevasi air, kita dapat mengetahui seberapa besar volume tampungan waduk berdsarkan elevasi dimana didapatkan menggunakan persamaan regresi polinomial orde 3 sebagai berikut:

$\mathrm{S}=0,0001 \mathrm{El}^{3}-0,0048 \mathrm{El}^{2}+0,0865 \mathrm{El}-0,5435$

\section{DEBIT ALIRAN MASUK}

Dalam memperhitungkan debit aliran yang akan masuk dalam suatu waduk, perlu dilakukan analisis waktu konsentrasi aliran dimana didapatkan dari akumalasi dari aliran permukaan dan aliran dalam saluran.

Berdasarkan persamaan linear maka dapat dihitung komulatif volume aliran yang masuk dalam waduk seperti pada Tabel 2 dan membentuk suatu hidrograf aliran masuk pada waduk seperti Gambar 7.

Tabel 2. Total volume aliran masuk pada waduk

\begin{tabular}{|c|c|c|c|c|c|}
\hline $\begin{array}{c}\text { Kumulatif } \\
\text { waktu } \\
\text { (menit) }\end{array}$ & $\begin{array}{c}\text { Aliran } \\
\text { masuk } \\
\text { (m/det) }\end{array}$ & $\begin{array}{c}\text { Rata-rata } \\
\text { aliran } \\
\text { masuk } \\
\left(\mathrm{m}^{2} / \text { det }\right)\end{array}$ & $\begin{array}{c}\text { Kumulatif } \\
\text { walktu } \\
\text { (detik) }\end{array}$ & $\begin{array}{c}\text { Volume } \\
\left(\mathrm{m}^{3}\right)\end{array}$ & $\begin{array}{c}\text { Kumulatif } \\
\text { Volume } \\
\left(m^{2}\right)\end{array}$ \\
\hline 0 & 0 & & 0 & & \\
\hline 4 & 2,87 & 1,43 & 240 & 344 & 344 \\
\hline 8 & 5,74 & 4,30 & 480 & 2.066 & 2.410 \\
\hline 12 & 8,61 & 7,17 & 720 & 5.165 & 7.576 \\
\hline 16 & 11,48 & 10,04 & 960 & 9.642 & 17.218 \\
\hline 20 & 14,35 & $12,9]$ & 1200 & 15.496 & 32.713 \\
\hline 24 & 17,22 & 15,78 & 1440 & 22.727 & 55.441 \\
\hline 28 & 20,09 & 18,65 & 1680 & 31.336 & 86.777 \\
\hline 32 & 22,96 & 21,52 & 1920 & 41.322 & 128.099 \\
\hline 36 & 25,83 & 24,39 & 2160 & 52.686 & 180.785 \\
\hline 40 & 28,70 & 27,26 & 2400 & 65.427 & 246.212 \\
\hline 44 & 31,57 & 30,13 & 2640 & 79.545 & 325.757 \\
\hline 46 & 33,00 & 32,28 & 2760 & 89.101 & 414.858 \\
\hline 50 & 31,26 & 32,13 & 3000 & 96.396 & 511.254 \\
\hline 54 & 29,53 & 30,40 & 3240 & 98.482 & 609.735 \\
\hline 58 & 27,79 & 28,66 & 3480 & 99.733 & 709.468 \\
\hline 62 & 26,05 & 26,92 & 3720 & 100.150 & 809.618 \\
\hline 66 & 24,32 & 25,19 & 3960 & 99.733 & 909.351 \\
\hline 70 & 22,58 & 23,45 & 4200 & 93.483 & 1.007 .835 \\
\hline 74 & 20,84 & 21,71 & 4440 & 96.400 & 1.104 .234 \\
\hline 78 & 19,11 & 19,97 & 4680 & 93.482 & 1.197 .716 \\
\hline 82 & 17,37 & 18,24 & 4920 & 89.731 & 1.287 .447 \\
\hline 86 & 15,63 & 16,50 & 5160 & 85.146 & 1.372 .593 \\
\hline 90 & 13,90 & 14,76 & 5400 & 79.728 & 1.452 .321 \\
\hline 94 & 12,16 & 13,03 & 5640 & 73.476 & 1.525 .797 \\
\hline 98 & 10,42 & 11,29 & 5880 & 66.390 & 1.592 .187 \\
\hline 102 & 8,69 & 9,55 & 6120 & 58.470 & 1.650 .657 \\
\hline 106 & 6,95 & 7,82 & 6360 & 49.717 & 1.700 .374 \\
\hline 110 & 5,21 & 6,08 & 6600 & 40.131 & 1.740 .505 \\
\hline 114 & 3,48 & 4,34 & 6840 & 29.710 & 1.770 .215 \\
\hline 118 & 1,74 & 2,61 & 7080 & 18.456 & 1.788 .671 \\
\hline 122 & 0.00 & 0.87 & 7320 & 6.363 & 1.795 .034 \\
\hline
\end{tabular}




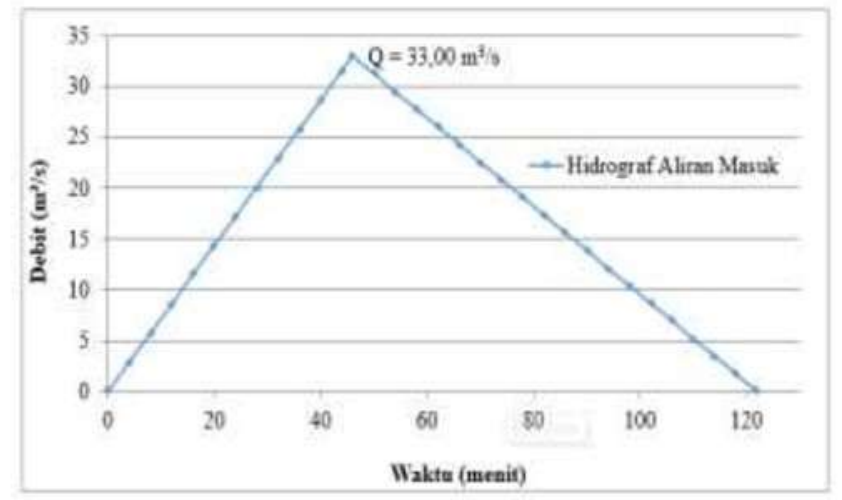

Gambar 7. Hidrograf aliran masuk metode linear

Total keselurahan volume yang masuk dalam waduk dengan penggunaan data cuaca ekstrim/curah hujan tertinggi adalah sebesar $\mathbf{1 . 7 9 5 . 0 3 4} \mathrm{m}^{3}$. Apabila dibandingkan dengan total kapasitas tampungan waduk yang yang hanya sebesar $\mathbf{7 9 4 . 9 0 0 , 4 5} \mathbf{~ m}^{3}$, maka dapat dikatakan saat ini waduk masih butuh penambahan kapasitas lagi.

\section{KAPASITAS TAMPUNGAN WADUK}

Kinerja daya tampung saluran keluaran (outflow) waduk maka dilakukan analisis seperti pada Tabel 3 yang diperbandingkan terhadap debit masukan (inflow) pada waduk.

Tabel 3. Debit aliran keluaran waduk

\begin{tabular}{|c|c|c|c|c|c|c|c|c|c|}
\hline \multirow{2}{*}{ Sestik } & \multicolumn{3}{|c|}{ Dimeneul } & \multirow{2}{*}{$\frac{2 w}{i m i}$} & \multirow{2}{*}{$\frac{\text { Kormest }}{(\mathrm{wa})}$} & \multirow{2}{*}{$\frac{\text { Kenwiege }}{\text { (tw) }}$} & \multirow{2}{*}{$\operatorname{lin}_{\text {iei }}$} & \multirow{2}{*}{$\frac{\text { Kerepated }}{\text { (awe) }}$} & \multirow{2}{*}{$\begin{array}{l}\text { Desil } \\
\text { intiv }\end{array}$} \\
\hline & $\begin{array}{l}\text { Leat } \\
\text { (m) }\end{array}$ & $\begin{array}{c}\text { Twese } \\
\text { (a) }\end{array}$ & rasjess & & & & & & \\
\hline $\begin{array}{l}\text { Mennesi } \\
\text { Pareasy }\end{array}$ & 4 & 200 & $\mathrm{~m}$ & $12, \infty$ & is & s.aps & 12 & 42 & stene \\
\hline
\end{tabular}

Hasil menunjukkan bahwa kapasitas saluran outflow adalah sebesar $57,90 \mathrm{~m}^{3} / \mathrm{s}$, apabila dibandingkan dengan besaran debit yang masuk (inflow) dimana bernilai $33,00 \mathrm{~m}^{3} / \mathrm{s}$ maka dapat dikatakan saluran outflow masih cukup memiliki kapasitas dalam menampung debit banjir dari dalam waduk.

\section{KESIMPULAN}

Berdasarkan hasil penelitian yang telah dilakukan dapat diambil kesimpulan sebagai berikut:

1. Pada kurva karakteristik didapatkan kapasitas tampungan dalam waduk Wonorejo adalah sebesar $0,795 \mathrm{MCM}$ atau $794.900,45 \mathrm{~m}^{3}$

2. Total keselurahan volume yang masuk dalam waduk dengan penggunaan data cuaca ekstrim/curah hujan tertinggi adalah sebesar
1.795.034 $\mathrm{m}^{3}$, apabila dibandingkan dengan total kapasitas tampungan waduk yang yang hanya sebesar 794.900,45 m³ , maka kinerja waduk dalam fungsi pengendalian banjir saat ini dapat menjadi kurang efektif dan butuh penambahan kapasitas lagi.

3. Kapasitas saluran pembuang (outflow) waduk adalah sebesar $57,90 \mathrm{~m}^{3} / \mathrm{s}$, apabila dibandingkan dengan besaran debit yang masuk (inflow) dimana sebesar $33,00 \mathrm{~m}^{3} / \mathrm{s}$ maka dapat dikatakan dimensi saluran outflow masih cukup memiliki kapasitas dalam menampung debit banjir dari dalam waduk.

\section{SARAN}

Saran yang diberikan berdasarkan hasil penelitian antara lain:

1. Perhitungan nilai koefisien kawasan dapat dilakukan secara detail dengan melakukan digitasi pada setiap penggunaan lahan di lokasi penelitian.

2. Masih terdapat beberapa kerusakan termasuk pada pintu air sehingga perlu perhatian khusus dalam melakukan perawatan secara berkala.

\section{DAFTAR PUSTAKA}

Chay Asdak. (2004). Hidrologi dan Pengelolaan Daerah Aliran Sungai. Gadjah Mada University Press. Yogyakarta.

Direktorat Jenderal Cipta Karya. (2012). Tata Cara Penyusunan Rencana Induk Drainase Perkotaan. Jakarta: Departemen Pekerjaan Umum.

Jayadi, R. (2012). Analisis Sumber Daya Air. Yogyakarta: Diktat Kuliah Program Pascasarjana Universitas Gadjah Mada.

Sudjarwadi. (2007). Pengembangan Sumberdaya Air. Yogyakarta: Biro Penerbit Teknik Sipil UGM.

Sri Harto Br. (1993). Analisis Hidrologi. Gramedia Pustaka Utama. Jakarta.

Suripin. (2004). Pengembangan Sistem Drainase yang Berkelanjutan. Andi Offset. Yogyakarta.

Susanto, H. (2018). Ketika Melihat Banjir Di Kota Balikpapan. Balikapan: P3K Kalimantan.

Triatmodjo, B. (2009). Hidrologi Terapan. Beta Offset. Yogyakarta. 